\title{
The Application of Flipped Classroom in Scene Simulation Method of Music Education
}

\author{
Jiaoxue Chao ${ }^{1, *}$ \\ ${ }^{1}$ Conservatory of Music, Shenyang, China \\ *Corresponding author email: guanghua.ren@gecacademy.cn
}

\begin{abstract}
Under the promulgation of the Ten-year Development Plan for Educational Informatization (2011-2020), the music education model undergoes a great breakthrough and development. Schools for music education have changed, as well as the mission, values and role allocation, which put forward higher requirements on the concept and method of music teaching. It is believed that music education should respect students' free personality, guide students to integrate music into life, learn music, enjoy music, and guide students from the perspective of life and daily learning methods. In this way, as a new teaching method and concept, is introduced to break through the limitations of traditional teaching time and space. As a result, can experience more space for self-study and communication. With the development of modern society, music teaching methods should be constantly improved. This paper explores the practice and method of combining flipped with scene simulation in music education to adapt to the development needs of contemporary music teaching.
\end{abstract}

\section{Keywords: Music Education, Flipped Classroom, Scene teaching Method}

\section{INTRODUCTION}

Many students at Woodland Park High School often miss school activities for reasons such as spending extra time on buses to and from school. They cannot keep up with their study progress due to their absence from classes. In 2007, the school's chemistry teachers, Jon Bergmann and Aaron Sams began making short video lessons and uploading PowerPoint slides on the Internet to help absentees teach themselves. More groundbreaking, they later had students watch videos and read handouts at home, leaving more time in class for difficult problems and hands-on experiments. Later, more and more schools came here to visit and exchange experiences. International institutions of higher learning such as MIT, Yale and Khan Academy chose this mode to record their open classes. More and more high-quality teaching resources emerged on the Internet, which pushed the development of flipped classrooms to another peak. The flipped classroom is gradually developed as a teaching model that moves most teacher-centred instruction out of the classroom to free up time for more student-centred learning activities [1].

Meanwhile, globalization accelerates music education to be aligned with the international standards and blueprint. Integrating foreign history and culture into the curriculum is a good illustration of this point. By making students understand the historical and cultural characteristics, musical development history and representative figures of other countries, students can improve their understanding of the musical characteristics of their own country and various ethnic groups and constantly improve their musical aesthetic ability. Contemporary music teaching can no longer be limited to the traditional musical structure, and teachers should encourage students to learn music in a broader world and improve their musical accomplishment. To achieve this goal, instructors must plan ahead, set scientific goals, achieve the optimal allocation of resources, stimulate students' music thinking, guides the student to use as an example. Music is compiled to fully embody the music education in the importance of global related colleges and universities should also strengthen the contact with music schools around the world. For example, introducing the excellent experience of other countries in China provides clues for the development of Chinese music.

The boost of music education entails the application of flipped classrooms. Its importance and innovation lies in that the better use of classroom time and enhancing the responsibility and efficiency of students through 
autonomous learning. When the pre-class tasks are fully completed, the leading role of innovative classroom situational teaching method can realize its maximum value. For example, the scene simulation method in music education is a teaching method integrating imagination, interest and science. When the teacher introduces a music story, students will use the professional skills they taught before class to create and perfect their own creation in the difficult part with their imagination. "Implementing flipped learning allows the students to spend more time supporting higher-level learning tasks such as a group discussion, while lower-level tasks such as knowledge and comprehension are completed independently outside the class" [2].

However, many instructors lack expertise and experience. First, most of the traditional teaching modes are indifferently input the information to the student in one direction while passively receive it. differences. Students do not take the initiative to learn, sum up their learning methods, but passively learn, so their learning potential, interest and thirst for knowledge are not stimulated, which greatly reduces the learning efficiency and teaching [3]. As a result, students have limited learning and understanding, and only use less spare time to watch videos.

Students should release their passion for learning during the short and exciting university study. Teachers cannot understand the flipped classroom concept and cannot connect it with music education well. The teacher should cultivate students' ability of independent study, independent thinking, independent creation and problem-solving. It is necessary for teachers to consider how to improve the performance of flipped.In music education by using scene teaching method. Therefore, this paper aims to improve teachers' performance in music education by adopting flipped classroom method.

\section{LITERATURE REVIEW}

\subsection{Flipped classroom}

In modern music teaching system, teachers often choose flipped as a new teaching method for music education. Some people think this teaching model is not as effective as the traditional one. However, several other studies have proved that flipped classroom has a great positive impact on modern music education. Students can learn independently, improve level of personalized judgment and learning ability. The relationship between students and teachers is no longer just knowledge grants, but teaching and learning. Bhagat administered quasi-experiments to reveal the efficacy of flipped classroom approach [4]. DeLozier and Rhodes articulate different types of in-class and out-of-class learning activities found in the literature of flipped classroom approach. These studies enhance our understanding of the effects and current practices of flipped classroom approach.

American scholar Edgar Dale once conducted a special statistical study according to the learning results of different learning methods and put forward the "learning pyramid" model. The results showed that students who studied by listening had acquired $5 \%$ of what they had learned two weeks later. Students who learn by reading have learned $10 \%$ of what they learned two weeks after finishing their studies. Students who used a combination of sound and images learned $20 \%$ of what they had learned two weeks after the study. Students who used a combination of hint and demonstration learned $30 \%$ of what they had learned two weeks later. Students who studied in groups learned $50 \%$ of what they learned two weeks after finishing their studies. Students who learn by the actual operation have acquired $75 \%$ of what they have learned two weeks after finishing their studies. Students who learn by teaching to others and using it quickly end up learning $90 \%$ of what they learned. Flipped classroom integrates these methods and them into each step of learning so that students can clearly know the steps and process of learning the knowledge and shortcomings they have mastered.

\subsection{Music education}

In recent years, China has made great achievements in music education. Many music educators, such as Wang Peiyuan and Huang $\mathrm{Zi}$, have made outstanding contributions to the development of China's music education. With the development of global economic integration, China is becoming more and more closely connected with the world. Western music education concepts and thoughts have an important impact on China. Music education in China has broken through the limitations of the past and developed into a popular course. Music education is a vital part of modern education. Strengthening music education reform is also an important measure to promote China's economic and cultural progress.

In the subject of teaching, music education irreplaceable advantages. It can provide students with abundant perceptual knowledge, which can deepen their cognition and understanding of beauty and cultivate their good aesthetic ability and rigorous logic. In addition, music teaching needs to rely on auditory response, which can increase students' emotional experience, especially can affect students' intelligence and thinking, cultivate students' creative ability.

\subsection{Scene simulation method}

The simulation method refers to the teacher eliciting or creating vivid scenes with a certain story and emotional color on the premise of purpose and design. 
The purpose is to help students establish scene thinking, creative thinking, can better understand the knowledge and skills taught by teachers and make students psychological function more scientific development. In our country elementary school music lesson, the teacher uses the game situation teaching method to combine the student lively and active characteristics.Through classroom games, for scene simulation method greatly increased the fun of music teaching to achieve good teaching results. Students can also feel the scenes and emotions of songs in music games so that students can better understand the content of works. Take the music textbook of grade one primary school as an example. In the first lesson Red Eyes, Green Eyes aroused students' curiosity, and the teacher successfully introduced the into the classroom.It aroused students' interest helped them understand the traffic regulations and common sense of life. This work vividly compares the watching rules of red light and green light.The teaching of this work focuses on developing students' sense of rhythm and singing ability. At the same time, students' inner hearing is cultivated through the training of rhythm. Before class, students should prepare the songs at home and make red cards and green cards respectively.In class, teachers lead students to carry out card games. First of all, the teacher explains the rules of the game to the students. When the music starts, the students raise the color sign in their hands according to the different content heard in the song. When the music sang the part about the red light, the students held up the red sign. When the music sang about the green light, the students held up the green sign.In the, the teacher can see the students' focused expression and happy smiling face.After the game, the teacher praised the students. At the same time, students can feel the happiness and rhythm of music and deeply understand the rules of crossing the road through the game teaching. This process not only enlivens the atmosphere and also helps teachers accurately achieve teaching objectives. It should be noted that the game should be consistent with the when teaching the game scenario. At the same time, the game content of scene simulation method should be combined with the age characteristics of students, and the game scene with appropriate difficulty should be set up.

As an important teaching method, scene simulation method is used by most teachers in music education. Flexible application of scene simulation method can make the boring curriculum content in a way that students can accept. Daily teaching activities, teachers can actively and innovatively use this teaching method to improve classroom mode and improve students' learning efficiency. Therefore, more and more teachers are using this method.

\section{DISCUSSION}

The application of flipped can help students to independently complete the construction of music knowledge system, find their own problems, and improve learning efficiency. It can also help teachers check students' learning ability so that teachers can carry out teaching practice in a more targeted way. Meanwhile scene simulation method establishes a bridge for music major students between profession and creativity. Scene design provides students a sense of stage and creativity in the process of music teaching. Take the initiative to learn music to realize the combination of emotion and cognition, especially the flipped classroom teaching mode. Before course, teachers assign video assignments to explain knowledge to students and give them some time to think increase students' understanding and imagination of the video. During the course, music scene teaching is carried out. Teachers let students feel a good music atmosphere in the classroom and gradually refine and decompose the music teaching content so that students can understand and feel music and then know, improve and interpret themselves.

\subsection{Improving students autonomous-learning ability}

Contemporary music teaching is no longer limited to the scope of traditional music. Music from all countries in the world with an open attitude, integrating the concept of globalization into the music curriculum. Openness is an advanced educational concept requires music teaching to be closely combined with social reality, combine musical life with real life, and encourage students to learn music in a broader world and improve their musical accomplishment.

To achieve this goal, instructors must plan in advance, set scientific goals, realize optimal allocation of resources, stimulate students' musical thinking, guide students to make full use of examples and networks, learn professional techniques from examples, create music and compose music by themselves, and fully reflect the practicality of flipped classroom in music education. Universities are actively strengthening the connection with music schools around the world, introducing the excellent experience of other Countries in China, providing clues for the development of education in China.

After learning materials, teachers need to share them with students and assign learning tasks to guide students to study and sort out knowledge in their spare time. First of all, teachers should use the network platform of the school to share the learning content and resources to the network platform, and students can download, watch and learn by themselves. During this period, they can sort out the knowledge structure mark the key points and difficulties encountered in self-study and share them with teachers through the network platform. Finally, the teacher collected and sorted out students' feedback, 
arranged related questions on the network platform according to the questions raised by students, and guided students to think twice and analyze their own questions, paving the way for classroom solutions and situational teaching.

\subsection{Enhancing Class Interaction}

The flipped class creates a vivid music professional class composed of smart students and innovative classroom content. It is unlike traditional class whose allocation of class time is mainly determined by the teacher and there is very little time for students to interact with each other. First of all, teachers divide students into different groups and internalize knowledge through group research and discussion. Meanwhile, teachers leave more time for students to discuss and create. Secondly, good course content is composed of two parts. Before the beginning of the class, there should be rhythmic music games to stimulate students' interest, which is also an important foundation for introducing the theme content of scene teaching method. The second part is that the teacher uses scene simulation method to introduce the theme song of this class. This teaching method greatly improves the enthusiasm and enthusiasm of students to participate in class. For example, in learning the rhythmic music game Eight Cups, a classic lesson of the teacher first plays the music that the students have prepared before in the classroom so that the students can perceive the rhythm and rhythm and review the self-taught content before class. After all the students are seated, the teacher will perform the standard rhythm of Eight Cups through the scene teaching method. During this period, the teacher will interact with the students, and the teacher will imitate the students once. Next, the teacher will set the time and assign the students to practice among groups and assign new composing tasks. The groups will discuss and compose new musical patterns based on the content of the teacher's performance. In the last part of the class, the teacher organized the students to share performances in groups. In innovative music education, teachers should realize the interaction of music content so that students can practice music in a strong music atmosphere and increase their understanding of pre-class learning knowledge. In the practice process, teachers use interactive music games to improve students' interest. If there are mistakes in the practice, students will correct them automatically until the end of the practice. Such a classroom form can better reflect the current situation of students, increase the mood of students learning music, create a music atmosphere, enhance the feelings of teachers and students.

\section{CONCLUSION}

Music education is an important part of quality education in China, but it still faces many difficulties at
present.It is mainly reflected in the lack of clear objectives, the content of music teaching book is not comprehensive enough, and the teaching mode is simple. Change this situation and break through the limitation of development, colleges and universities need to set clear goals, speed up innovation music teaching.Establish the concept of modern music education. Improve the effectiveness of music education, pay attention to educational practice. Improve students' music practice ability.Meanwhile, a large number of new educational ideas and models emerge endlessly, but the concept and method of improving music education is the key. A brand new teaching mode, is a breakthrough and subversion of the traditional teaching mode and meets the requirements of the development of science and technology in modern society. Therefore, in the development of music education, schools need to introduce the, pay attention to cultivate students' interest, stimulate their enthusiasm, cultivate correct ideas, and promote students' all-round development. Based on the original teaching, schools and teachers should work together to introduce new ideas and methods to improve the effect of music teaching.

\section{REFERENCES}

[1] T.Lag , R.G.Sale, Does the Flipped Classroom Improve Student Learning and Satisfaction? A Systematic Review and Meta-Analysis,in AERA Open,vol.5,No.3,2019,pp.1-17,DOI:10.1177/23328 58419870489

[2] Z.Zainuddin1,S.H.Halili , Flipped Classroom Research and Trends from Different Fields of Study, in International Review of Research in Open and Distributed Learning,Vol.17, No3,2016

[3] C.K.Lo,K.F.Hew,A critical review of flipped classroom challenges in K-12 education: possible solutions and recommendations for future Research , in Lo and Hew Research and Practice in Technology Enhanced Learning,Vol.12,No.4,2017, DOI: 10.1186/s41039-016-0044-2

[4] J.Nouri,The flipped classroom: for active, effective and increased learning - especially for low achievers, in Nouri International Journal of Educational Technology in Higher Education,Vol.13,No.33,DOI:10.1186/s41239-0160032-Z

[5] E.Cabi,The Impact of the Flipped Classroom Model on Students' Academic Achievement,in International Review of Research Open and Distributed Learning, Vol.19,No.3,2018 
[6] L.C.Kwan,Student learning and engagement in Mathematics flipped classrooms:An action research study in a secondary school

[7]

$$
\text { G.C.ying,Application }
$$

of "Scene-Case-Role-Interaction" Teaching Method in College Practical English, in:Francis Academic Press, UK 275,DOI: 10.25236/iemb.2021.046

[8] G.Waddell1,R. Perkins,A.Williamon,The Evaluation Simulator: A New Approach to Training Music Performance Assessment in TECHNOLOGY REPORT Vol.10,Article 557,2019,Dol:10.3389/fpsyg.2019.00557 